Supporting Information for

\title{
Potential-dependent Superlubricity of Ionic Liquids on Graphite Surface
}

\author{
Yunxiao Zhang ${ }^{1}$, Mark W. Rutland ${ }^{2,3}$, Jiangshui Luo ${ }^{4}$, Rob Atkin ${ }^{1 *}, \mathrm{Hua} \mathrm{Li}^{1,5^{*}}$
}

${ }^{1}$ School of Molecular Sciences, The University of Western Australia, Perth, Western

Australia, Australia.

${ }^{2}$ School of Chemical Science and Engineering, KTH Royal Institute of Technology, SE100

44 Sweden, and

${ }^{3}$ Surfaces, Processes and Formulation, RISE Research Institutes of Sweden, SE114 86

Stockholm, Sweden

${ }^{4}$ College of Materials Science and Engineering, Sichuan University, 610065 Chengdu, China

${ }^{5}$ Centre for Microscopy, Characterisation and Analysis, The University of Western Australia, Perth, Western Australia, Australia.

Email: Hua.Li@uwa.edu.au; Rob.Atkin@uwa.edu.au 


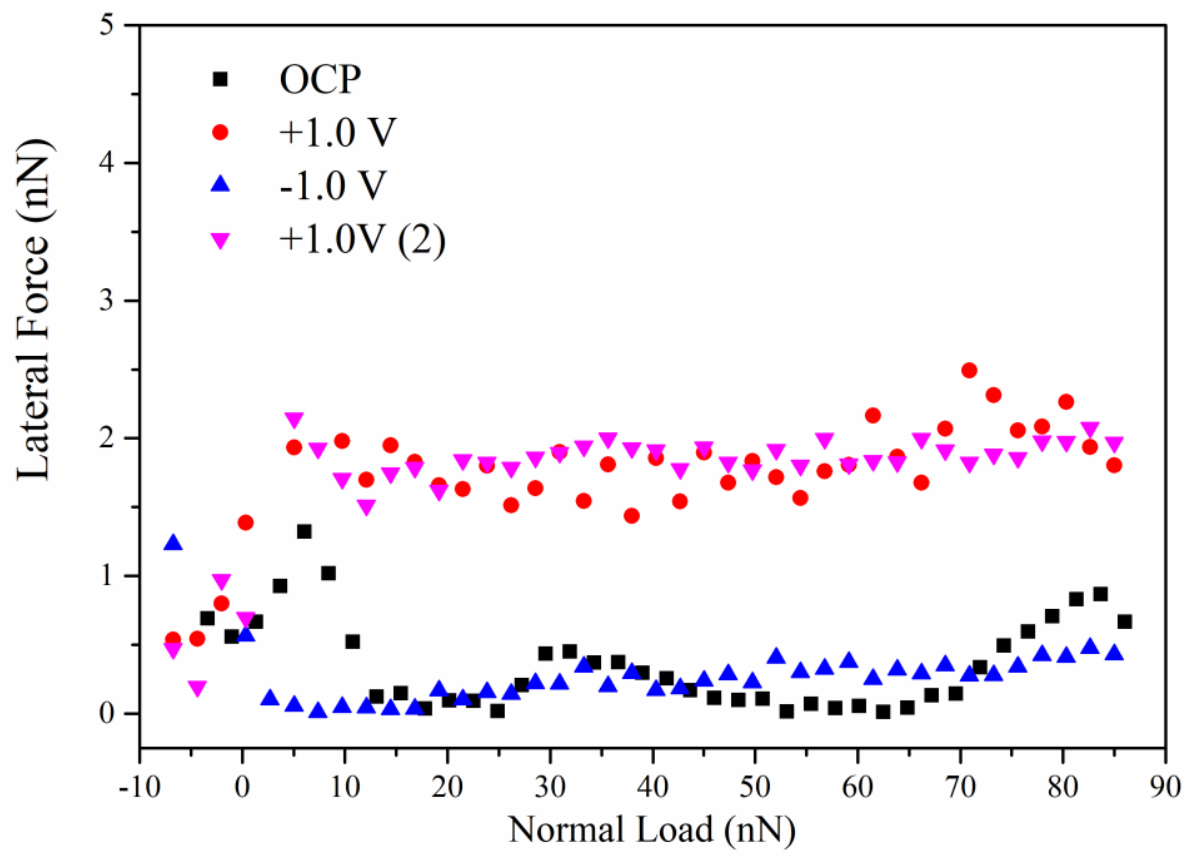

Figure S1 Lateral force vs. normal load of four ILs potentials of $\left[\mathrm{P}_{6,6,6,14}\right]\left[\left({ }^{\mathrm{i}} \mathrm{C}_{8}\right)_{2} \mathrm{PO}_{2}\right]$

Figure $\mathrm{S} 1$ shows the lateral forces of $\left[\mathrm{P}_{6,6,6,14}\right]\left[\left({ }^{\mathrm{i}} \mathrm{C}_{8}\right)_{2} \mathrm{PO}_{2}\right]$ lubricating on charged HOPG surfaces, and the applied potential order is $\mathrm{OCP},+1.0 \mathrm{~V},-1.0 \mathrm{~V}$ then back to $+1.0 \mathrm{~V}$. The data are collected after a potential is set for $10 \mathrm{~min}$. Vanishing frictions are detected for OCP and $-1.0 \mathrm{~V}$, and relative higher friction for $+1.0 \mathrm{~V}$. Furthermore, friction returned to the high value when surface potential switches from $-1.0 \mathrm{~V}$ to $+1.0 \mathrm{~V}$ (labelled as $+1.0 \mathrm{~V}(2)$ ). This confirms the potential-dependent friction behaviour of ILs is reproducible when surface potentials switch from $+1.0 \mathrm{~V}$ to $-1.0 \mathrm{~V}$ and then back to $+1.0 \mathrm{~V}$. This reveals that ions adsorption and desorption occur within $10 \mathrm{~min}$ (the dwell time once a potential is set).

\section{Johnson-Kendall-Roberts (JKR) Model Fitting}

According to JKR model, ${ }^{1-2}$ contact radius $a$, as shown in equation 1 , changes with load $F_{\mathrm{N}}$, where $a_{0}$ is the initial radius of the AFM probe $(\sim 8 \mathrm{~nm})$ and $L_{\mathrm{c}}$ is the adhesion obtained from the retraction of AFM normal force curves.

$$
a=a_{0} \cdot\left(\frac{1+\sqrt{1-F_{N} / L_{C}}}{2}\right)^{2 / 3}
$$


Contact area $A$ is given by

$$
A=\pi a^{2}
$$

The total lateral force $\left(F_{\mathrm{LT}}\right)$, i.e. shear forces between surfaces, under low load is proportional to contact area and could be described by the following equation, ${ }^{3}$

$$
F_{\mathrm{LT}}=S_{\mathrm{c}} \cdot \pi a^{2}
$$

Therefore, $F_{\mathrm{LT}}$ could be related to $F_{\mathrm{N}}$ when combining equations [S1], [S2] and [S3] as follows:

$$
F_{\mathrm{LT}}=S_{\mathrm{c}} \cdot \pi a_{0}^{2} \cdot\left(\frac{1+{\sqrt{1-F_{N} / L_{C}}}^{4 / 3}}{2}\right.
$$

The lateral force vs load data obtained from AFM measurements are fitted with equation [S4] using $L_{\mathrm{c}}$ and $S_{\mathrm{c}}$ as free parameters. The fitted curves are plotted with measured friction data, as shown in Figure S2; the fitted $L_{\mathrm{c}}$ values and $L_{\mathrm{c}}$ values measured from the retraction normal force curves are listed in Table S1. For all four ILs investigated, the $L_{\mathrm{c}}$ values obtained from JKR fits are in good agreement with the measured values, which indicate that the lateral force data follow the JKR model fairly well for these systems. 


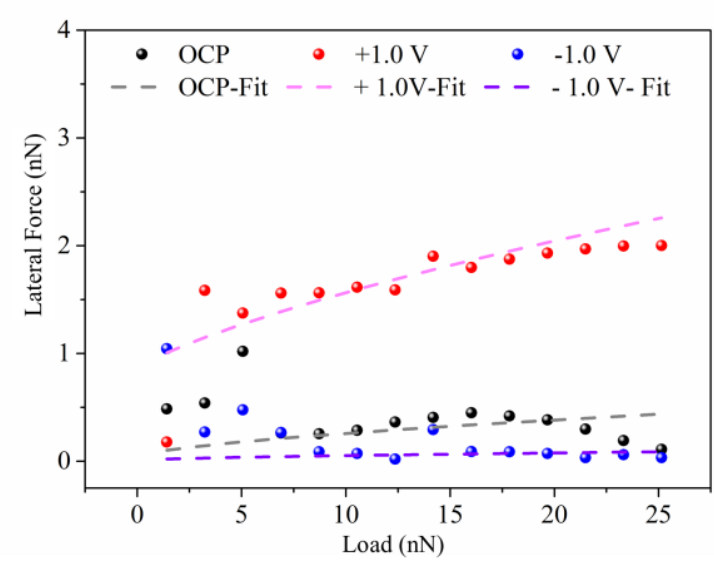

(a) $\left[\mathbf{P}_{6,6,6,14}\right]\left[\left(\mathrm{C}_{8}\right)_{2} \mathrm{PO}_{2}\right]$

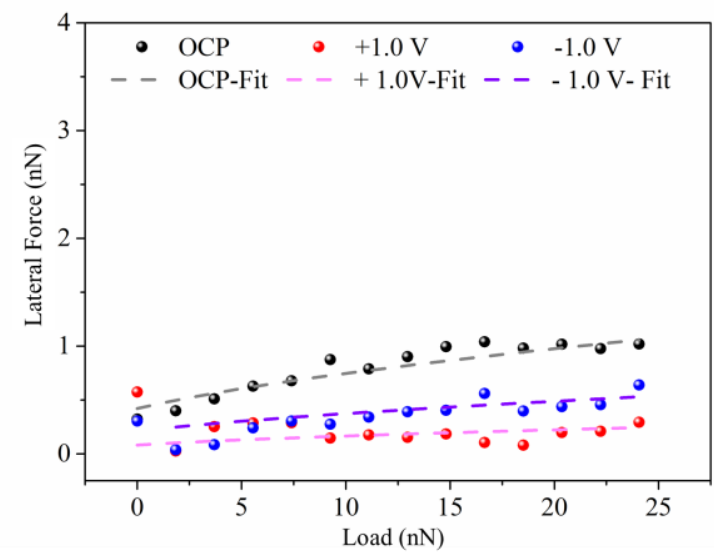

(c) $\left[\mathbf{P}_{6,6,6,14}\right][$ TFSI $]$

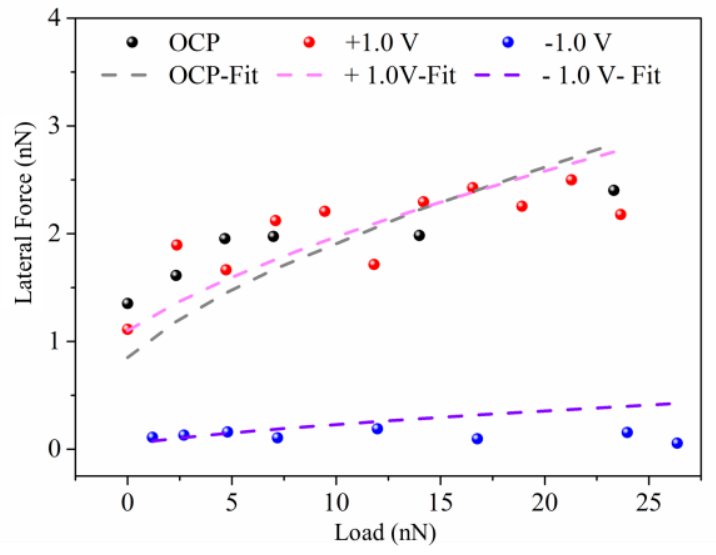

(b) $\left[\mathbf{P}_{6,6,6,14}\right][$ BEHP $]$

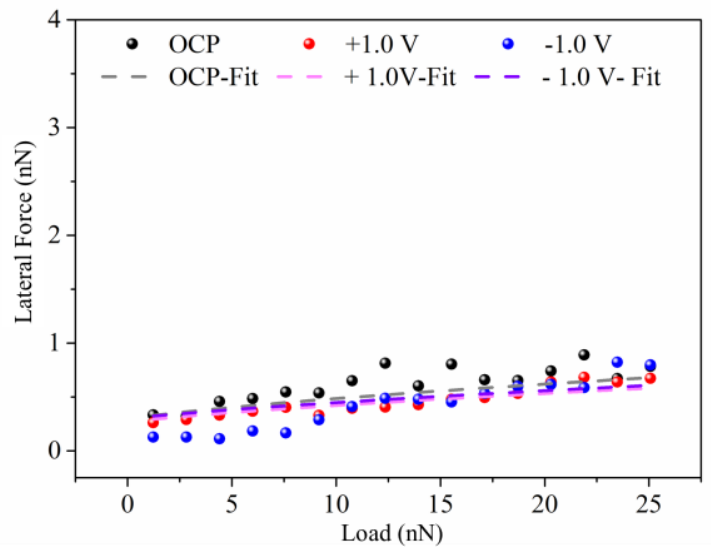

(d) $\left[\mathbf{P}_{4,4,4,1}\right][$ TFSI $]$

Figure S2 JKR fits of the lateral force vas load data for four ILs at OCP, $-1.0 \mathrm{~V}$ and $+1.0 \mathrm{~V}$ on HOPG: (a) $\left[\mathrm{P}_{6,6,6,14}\right]$ $\left[\left({ }^{\mathrm{i}} \mathrm{C}_{8}\right)_{2} \mathrm{PO}_{2}\right]$, (b) $\left[\mathrm{P}_{6,6,6,14}\right][\mathrm{BEHP}]$, (c) $\left[\mathrm{P}_{6,6,6,14}\right][\mathrm{TFSI}]$ and (d) $\left[\mathrm{P}_{4,4,4,1}\right][\mathrm{TFSI}]$.

Table S1 $L_{\mathrm{c}}$ obtained from JKR fits and AFM normal force measurement.

\begin{tabular}{|c|c|c|c|c|c|c|c|c|c|c|c|c|}
\hline & \multicolumn{3}{|c|}{$\left.\left[\mathrm{P}_{6,6,6,14}\right]\left[{ }^{\mathrm{i}} \mathrm{C}_{8}\right)_{2} \mathrm{PO}_{2}\right]$} & \multicolumn{3}{|c|}{$\left[\mathrm{P}_{6,6,6,14}\right][\mathrm{BEHP}]$} & \multicolumn{3}{|c|}{$\left[\mathrm{P}_{6,6,6,14}\right][\mathrm{TFSI}]$} & \multicolumn{3}{|c|}{$\left[\mathrm{P}_{4,4,4,1}\right][\mathrm{TFSI}]$} \\
\hline & $\mathrm{OCP}$ & $+1 \mathrm{~V}$ & $-1 \mathrm{~V}$ & OCP & $+1 \mathrm{~V}$ & $-1 \mathrm{~V}$ & OCP & $+1 \mathrm{~V}$ & $-1 \mathrm{~V}$ & OCP & $+1 \mathrm{~V}$ & $-1 \mathrm{~V}$ \\
\hline $\begin{array}{l}L_{\mathrm{c}(\mathrm{AFM})} \\
(\mathrm{nN})\end{array}$ & 1.6 & 2.9 & 0.8 & 0.1 & 2.9 & 0.1 & 4.4 & 2.0 & 3.1 & 2.3 & 4.5 & 5.3 \\
\hline $\begin{array}{l}L_{\mathrm{C}(\mathrm{JKR})} \\
(\mathrm{nN})\end{array}$ & 1.6 & 2.9 & 0.8 & 0.3 & 3.0 & 0.3 & 3.0 & 2.0 & 3.0 & 4.0 & 4.5 & 5.3 \\
\hline
\end{tabular}

References

1. Carpick, R. W.; Ogletree, D. F.; Salmeron, M., A General Equation for Fitting Contact Area and Friction vs Load Measurements. Journal of Colloid and Interface Science: 1999.

2. Bogdanovic, G.; Tiberg, F.; Rutland, M. W., Sliding Friction between Cellulose and Silica Surfaces. Langmuir 2001, 17 (19), 5911-5916. 
3. Li, H.; Choi, Y. S.; Rutland, M. W.; Atkin, R., Nanotribology of hydrogels with similar stiffness but different polymer and crosslinker concentrations. Journal of Colloid and Interface Science 2020, $563,347-353$. 